\title{
Sistem Pendukung Keputusan Penentuan Penerima Bantuan Bedah Rumah Menggunakan Metode Weighted Product Pada Kecamatan Borbor
}

\author{
Wasindo Hutahaean ${ }^{1 *}$, Penda Sudarto Hasugian ${ }^{2}$ \\ 1,2 STMIK Pelita Nusantara \\ Jl. Iskandar Muda No. 1 Medan 20154 Indonesia \\ Corresponding author's e-mail: wasindohutahaean@gmail.com
}

\begin{abstract}
Abstrak - Di pedesaan masih banyak ditemukan rumah warga yang tidak layak huni dan hal ini disebabkan oleh faktor taraf hidup masyarakat yang masih hidup sederhana dan mempunyai penghasilan dibawah ratarata,kondisi tersebut membuat banyaknya rumah warga yang tidak layak huni yang perlu di bedah melalui bantuan bedah Rumah. Metode Weighted Product dapat membantu dalam mengambil keputusan akan tetapi perhitungan dengan menggunakan metode Weighted Product ini hanya menghasilkan nilai terbesar yang akan terpilih sebagai alternatif yang terbaik. Perancangan pengambilan keputusan penerima bantuan bedah rumah pada Dinas Perumahan dan Kawasan Permukiman berdasarkan kriteria yaitu WNI, penghasilan dibawah rata”, sudah berkerluarga, Memiliki atau menguasai tanah, Belum memiliki rumah atau memiliki dan menghuni rumah tidak layak huni menggunakan metode Weighted Product. Perancangan aplikasi mengunakan bahasa pemrograman PHP dan MySQL
\end{abstract}

Kata kunci: Penerima Bantuan, nilai terbesar, SPK, Weighted Product

Abstract - In rural areas there are still many residents 'houses that are unfit for habitation and this is due to the factor of the standard of living of people who are still living simply and have below average income, these conditions make many residents' houses unfit for habitation that need to be repaired through assistance Home renovation. The Weighted Product method can help in making decisions, but the calculation using the Weighted Product method only produces the largest value which will be selected as the best alternative. The design of decision-making for housing renovation assistance recipients at the Housing and Settlement Areas is based on criteria, namely Indonesian citizens, below average income, belonging to a family, owning or controlling land, not having a house or owning and living in an uninhabitable house using the Weighted Product method. Application design using the programming language PHP and MySQL

Keywords: Beneficiary, greatest value, SPK, Weighted Product

\section{Pendahuluan}

Dinas perumahan dan kawasan pemukiman merupakan instansi yang didirikan oleh Pemerintah yang mempunyai visi untuk mewujudkan penataan ruang yang terpadu, terkendali dan dinamis menuju negara yang maju diantaranya dengan melalui program bantuan bedah rumah yang rutin diadakan tiap tahun. Program bantuan bedah rumah harus diberikan kepada penerima yang layak dan pantas untuk mendapatkannya. Banyaknya masyarakat yang berhak menerima bantuan bedah rumah menjadikan Dinas Perumahan dan Kawasan Permukiman harus sangat selektif untuk memberikan bantuan bedah rumah. Permasalahan yang sering muncul yaitu kurang tepatnya penyaluran bantuan bedah rumah terhadap masyarakat karena adanya unsur hubungan kekeluargaan, misalnya masyarakat yang sebenarnya tidak layak mendapatkan bantuan bedah rumah tetapi mendapatkan bantuan bedah rumah, sebaliknya masyarakat yang berhak mendapatkan bantuan bedah rumah tetapi tidak mendapatkan bantuan bedah rumah.Penilaian secara kuantitatif sering dianggap mengecewakan karena sulitnya mengukur parameter-parameter yang ada. Di lain pihak, Dinas Perumahan dan Kawasan Permukiman menginginkan data yang real atau sesusai dengan kriteria sehingga dapat memberikan umpan balik dan perbaikan yang cepat. Kriteria penerima program bedah rumah sesuai dengan Peraturan Pemerintah saat ini yaitu WNI,penghasilan dibawah UMK (yaitu Rp.2.600.000), sudah berkerluarga,Memiliki atau menguasai tanah (kurang dari 72 meter persegi), memiliki rumah tidak layak huni (lantai kayu sudah rapuh,dingding kayu sudah lapuk,dan atap sudah rapuh). Kriteria-kriteria tersebut yang akan dijadikan pertimbangan untuk menentukan penerima bantuan bedah rumah, untuk itu diperlukan suatu sistem pendukung keputusan (SPK) yang dapat memperhitungkan segala kriteria yang mendukung pengambilan keputusan guna membantu, mempercepat dan mempermudah proses pengambilan keputusan dalam pemberian bantuan bedah rumah dengan menggunakan metode Weighted Product.[1].

Penelitian Rancangan Sistem Pendukung Keputusan Penentuan Penerima Bantuan Program Pemerintah menjelaskan Sistem Pendukung Keputusan (Decision Support System) adalah sistem informasi berbasis 
komputer yang menyediakan dukungan informasi yang interaktif bagi manajer dan praktisi bisnis selama proses pengambilan keputusan [2]. Penelitian DSS Pemilihan Penerima Bantuan Perbaikan Rumah dengan Metode Weighted Product menguraiakn metode WP menggunakan tekhik perkalian untuk menggunakan perkalian untuk menghubungkan rating atribut, dimana rating setiap atribut harus dipangkatkan dulu dengan bobot atribut yang bersangkutan . proses ini sama halnya dengan proses normalisasi [3]. Metode Weighted Product merupakan metode yang sering digunakan untuk membantu dalam menentukan goal atau keputusan [4]. Konsep yang digunakan adalah dengan pembobotan dengan rating suatu variabel penilai.Metode Weighted Product (WP) menggunakan perkalian untuk menghubungkan rating atribut, dimana rating setiap atribut harus dipangkatkan dulu dengan bobot atribut yang bersangkutan [5] [6].

\section{Tinjauan Pustaka}

2.1. Sistem Pendukung Keputusan (Decision Support System)

Sistem merupakan kumpulan elemen yang saling berkaitan yang bertanggung jawab memproses masukan (input) sehingga menghasilkan keluaran (output) [7]. Sistem Pendukung Keputusan (SPK) Decision Support Sistem (DSS) adalah sistem informasi interaktif yang menyediakan informasi,pemodelan, dan pemanipulasian data Sistem pendukung keputusan bukan merupakan alat pengambilan keputusan, melainkan merupakan sistem yang membantu pengambil keputusan dengan melengkapi dengan informasi data dari yang telah diolah dengan relevan dan diperlukan untuk membuat keputusan tentang suatu masalah dengan lebih cepat dan akurat [8].

2.2 Metode Weighted Product

Metode WP merupakan metode dengan kepanjangan Weighted Product [9]. Metode ini sering digunakan untuk membantu dalam menentukan goal atau keputusan. Konsep yang digunakan adalah dengan pembobotan dengan rating suatu variabel penilai.Metode Weighted Product (WP) menggunakan perkalian untuk menghubungkan rating atribut, rating setiap atribut harus dipangkatkan dulu dengan bobot atribut yang bersangkutan [10]. Proses tersebut sama halnya dengannormalisasi.Metode Weighted Product dapat membantu dalam mengambil keputusan akan tetapi perhitungan dengan menggunakan metode weighted product ini hanya menghasilkan nilai terbesar yang akan terpilih sebagai alternatif yang terbaik [11]. Perhitungan akan sesuai dengan metode ini apabila alternatif yang terpilih memenuhi kriteria yang telah ditentukan [12].

\section{Metode Penelitian}

Tahap penelitian sebagai berikut:

a. Indentifikasi Masalah, proses identifikasi masalah, mengadakan survei pendahuluan dan menentukan objek penelitian yang berkaitan dengan topik permasalahan penelitian.

b. Pengumpulan Data

Dalam pelaksanaan penelitian ini dibutuhkan dua jenis data yaitu data primer, mengumpulkannya secara langsung, dan Data sekunder, diperoleh atau dikumpulkan dari berbagai sumber

c. Penerapan Metode, Weigthted Product adalah metode penyelesaian dengan menggunakan perkalian untuk menghubungkan rating atribut, dimana rating harus dipangkatkan terlebih dahulu dengan bobot atribut yang bersangkutan. Langkah-langkah yang dilakukan dalam menerapkan metode Weighted Product:

1. Menentukan kriteria-kriteria yang akan dijadikan acuan dalam pengambilan keputusan.

2. Menentukan input awal dan input akhir untuk merubah nama inputan menjadi nilai rating kecocokan danmenentukan bobot setiap kriteria.

3. Mengubah inputan data calon penerima bantuan bedah rumah menjadi nilai rating kecocokan.

4. Melakukan perbaikan bobot dari setiap kriteria dengan cara menjumlahkan bobot setiap kriteria yang dilanjutkandengan setiap bobot awal kriteria dibagi dengan hasil penjumlahan bobot kriteria

5. Menentukan nilai vektor $\mathrm{S}$ alternatif data calon penerima bantuan bedah rumah dengan cara mengalikan data nilai ratingkecocokan yang berpangkat positif dari hasil perbaikan bobot kriteria

d. Analisa dan Perancangan

e. Impelementasi Sistem

\section{Hasil dan Pembahasan}

Analisa kebutuhan sistem dibutuhkan 2 jenis kebutuhan yaitu kebutuhan fungsional dan kebutuhan nonfungsional.

1. Kebutuhan Fungsional, kebutuhan fungsional adalah fungsi-fungsi yang harus dipenuhi pada aplikasi yang dirancang, yaitu:

a. Sistem harus dapat menerima inputan data penentuan Penerima bantuan Bedah Rumah dan bobot kriteria yang telah ditentukan.

b. Sistem dapat menentukan penerima Bantuan Bedah Rumah yang sesuai dengan kriteria berdasarkan metode 
WP.

c. Sistem harus dapat menampilkan hasil perhitungan penentuan penerima bantuan bedah rumah berdasarkan metode WP.

2. Kebutuhan Non-fungsional, kebutuhan Non-fungsional adalah kebutuhan yang harus dipenuhi agar aplikasi yang dirancang mendapat respon yang baik dari pengguna aplikasi, seperti :

a. Sistem dapat melakukan perhitungan menentukan penerima bantuan bedah rumah sesuai dengan kriteria dari user dengan cepat dan tepat.

b. Sistem yang dibuat harus mudah digunakan sehingga sistem dapat dioperasikan dengan baik oleh user.

Metode Weighted Product adalah metode penyelesaian dengan menggunakan perkalian untuk menghubungkan rating atribut, dimana rating harus dipangkatkan terlebih dahulu dengan bobot atribut yang bersangkutan.

Tabel 1. kriteria penerima bantuan bedah rumah

\begin{tabular}{|l|l|l|}
\hline Kriteria & Keterangan & Jenis \\
\hline C1 & WNI & Benefit \\
\hline C2 & Penghasilan dibawah UMK & Cost \\
\hline C3 & Sudah berkeluarga & Benefit \\
\hline C4 & Menguasai tanah & Benefit \\
\hline C5 & $\begin{array}{l}\text { Memiliki rumah tidak layak } \\
\text { huni }\end{array}$ & Benefit \\
\hline
\end{tabular}

\begin{tabular}{|c|c|}
\hline Nilai bobot & Keterangan \\
\hline 0 & Sangat rendah \\
\hline 0,20 & Rendah \\
\hline 0,40 & Sedang \\
\hline 0,60 & Cukup \\
\hline 0,80 & Baik \\
\hline 1,00 & Sangat baik \\
\hline
\end{tabular}

Kriteria-kriteria yang harus dipenuhi calon penerima bantuan bedah rumah :

a. Kriteria WNI (C1)

Kriteria WNI merupakan persyaratan yang ditentukan dalam pengambilan keputusan.Berdasarkan ketentuan Dinas Perumahan dan kawasan Pemukiman berhak menerima bantuan bedah rumah adalah Warga Negara Indonesia (WNI).

b. Kriteria penghasilan dibawah UMK (C2), Kriteria penghasilan dibawah UMK merupakan salah satu persyaratan yang dibutuhkan untuk pengambilan keputusan, Semakin tinggi jumlah penghasilan maka bobot juga semakin rendah

c. Kriteria sudah berkelurga (C3), Kriteria sudah berkeluarga merupakan persyaratan yang ditentukan dalam pengambilan keputusan. Berdasarkan ketentuan Dinas Perumahan dan kawasan Pemukiman Yang berhak menerima bantuan bedah rumah adalah Warga yang sudah berkeluarga

d. Kriteria menguasai tanah (C4), Kriteria menguasai tanah merupakan persyaratan yang ditentukan dalam pengambilan keputusan. Berdasarkan ketentuan Dinas Perumahan dan kawasan Pemukiman Yang berhak menerima bantuan bedah rumah adalah Warga yang menguasai tanah

e. Kriteria memiliki rumah tidak layak huni, Kriteria memiliki rumah tidak layak huni merupakan persyaratan yang ditentukan dalam pengambilan keputusan. Berdasarkan ketentuan Dinas Perumahan dan kawasan Pemukiman Yang berhak menerima bantuan bedah rumah adalah Warga yang memiliki rumah tidak layak huni

Menentukan Bobot Preferensi atau tingkat Kepentigan (W) setiap kriteria, W = [1.00 (C1);0.80 (C2); 1,00 (C3); 0,80 (C4); 1,00 (C5)]. Membuat tabel rating kecocokan dari setiap alternatif pada setiap kriteria. Berikut ini diambil sampel 10 data warga calon penerima bantuan bedah rumah yang akan diuji berdasarkan kriteria yang telah ditentukan.

Tabel 3. Data Sampel

\begin{tabular}{|l|l|l|l|l|l|}
\hline Alternatif & WNI & $\begin{array}{c}\text { Penghasilan dibawah } \\
\text { UMK }\end{array}$ & Berkeluarga & $\begin{array}{c}\text { Menguasai } \\
\text { tanah }\end{array}$ & $\begin{array}{c}\text { Memiliki rumah tidak layak } \\
\text { huni }\end{array}$ \\
\hline Parasman Psb(A1) & WNI & Rp 2.000.000 & Berkeluarga & Ya & Ya \\
\hline Sartono Hth(A2) & WNI & Rp 3.000.000 & $\begin{array}{c}\text { Belum } \\
\text { Berkeluarga }\end{array}$ & Ya & Ya \\
\hline Hulman Lubis (A3) & WNI & Rp 1.800.000 & $\begin{array}{c}\text { Belum } \\
\text { Berkeluarga }\end{array}$ & Ya & Ya \\
\hline Ferdinan Tbn (A4) & WNI & Rp 2.200.000 & Berkeluarga & Ya & Ya \\
\hline Pardamean P (A5) & WNI & Rp 2.600.000 & Berkeluarga & Sengketa & Ya \\
\hline $\begin{array}{c}\text { Jardiman Hth (A6) } \\
\text { WNI }\end{array}$ & Rp 2.000.000 & $\begin{array}{c}\text { Belum } \\
\text { Berkeluarga }\end{array}$ & Ya & YaS \\
\hline Wilmar S (A7) & WNI & Rp 2.000.000 & Berkeluarga & Ya & Tidak \\
\hline Binsar Pardosi (A8) & WNI & Rp 2.300.000 & Berkeluarga & Tidak & Ya \\
\hline Hendra lubis (A9) & WNI & Rp 2.250.000 & Berkeluarga & Ya & Ya \\
\hline $\begin{array}{c}\text { Martamarbun } \\
\text { (A10) }\end{array}$ & WNI & Rp 1.600.000 & Berkeluarga & Tidak & Ya \\
\hline
\end{tabular}


Normalisasi atau perbaikan bobot, perhitungan metode weighted product yang dimulai dengan cara membuat perbaikan bobot kriteria sesuai nilai $\Sigma \mathrm{Wi}=1$. Menentukan nilai vektor $\mathrm{S}=\mathrm{S} 1=\prod_{j=1}^{n} x i j^{\mathrm{wij}}$. Setelah didapat hasil dari pencarian nilai skor, selanjutnya menentukan nilai vektor dari setiap alternatif.Nilai vektor didapatkan dari hasil skor setiap alternatif dibagi seluruh jumlah skor sesuai dengan persamaan. Proses pencarian nilai vector.

Tabel 4. Hasil Perhitungan V

\begin{tabular}{|c|c|c|}
\hline No & Alternatif & $\mathrm{Vi}$ \\
\hline 1. & $\mathrm{~A} 1$ & $\mathrm{~V} 1=0.114$ \\
\hline 2. & $\mathrm{~A} 2$ & $\mathrm{~V} 2=0.103$ \\
\hline 3. & $\mathrm{~A} 3$ & $\mathrm{~V} 3=0,081$ \\
\hline 4. & $\mathrm{~A} 4$ & $\mathrm{~V} 4=0.114$ \\
\hline 5. & $\mathrm{~A} 5$ & $\mathrm{~V} 5=0.106$ \\
\hline 6. & $\mathrm{~A} 6$ & $\mathrm{~V} 6=0.081$ \\
\hline 7. & $\mathrm{~A} 7$ & $\mathrm{~V} 7=0,102$ \\
\hline 8. & $\mathrm{~A} 8$ & $\mathrm{~V} 8=0,090$ \\
\hline 9. & $\mathrm{~A} 9$ & $\mathrm{~V} 9=0,114$ \\
\hline 10. & $\mathrm{~A} 10$ & $\mathrm{~V} 10=0,090$ \\
\hline
\end{tabular}

Tabel 5. Hasil Perangkingan

\begin{tabular}{|c|c|c|}
\hline Rangking & Alternatif & Vi \\
\hline 1. & A1 & V1=0.114 \\
\hline 2. & A4 & V4=0.114 \\
\hline 3. & A9 & V9=0.114 \\
\hline 4. & A5 & V2=0.106 \\
\hline 5. & A2 & V7 $=0.103$ \\
\hline 6. & A7 & V8=0.102 \\
\hline 7. & A8 & V10 $=0,090$ \\
\hline 8. & A10 & V5 $=0,090$ \\
\hline 9. & A3 & V3 $=0,081$ \\
\hline 10. & A6 & V6 $=0,081$ \\
\hline
\end{tabular}

Alternatif calon penerima bantuan yang layak menerima bantuan bedah rumah adalah alternatif A1, A4 dan A9.

Tampilan sistem yang dihasilkan, Gambar 1 dan Gambar 2.

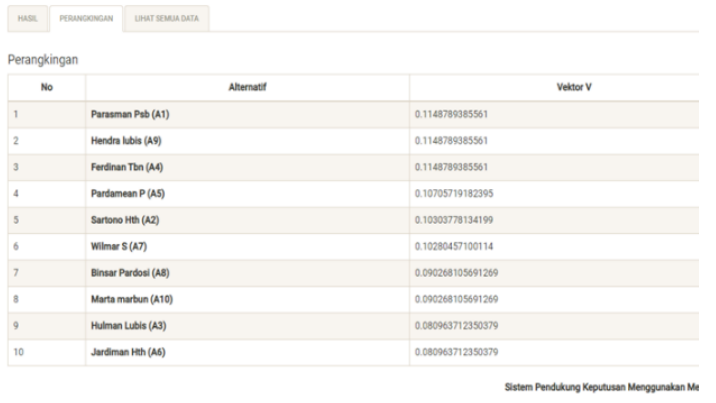

Gambar 1. Form Perangkingan

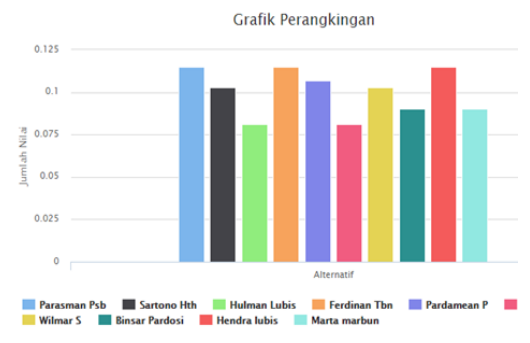

Gambar 2. Grafik Perangkingan

\section{Kesimpulan}

Kesimpulan dari penelitian :

1. Sistem pendukung keputusan penentuan penerima bantuan bedah rumah menggunakan metode weighted product terkomputerisasi dan pengujian hasil penentuan penerima bantuan bedah rumah akan lebih mudah dapat diketahuidan membantu pihak 'Dinas Perumahan dan Kawasan Permukiman dalam meyelesaikan tugas secara objektif dan efesien.

2. Metode weighted productdapat membantu menyelesaikan masalah untuk penentuan penerima bantuan bedah rumah.

\section{Daftar Pustaka}

[1] B. Satria and L. Tambunan, "Sistem Pendukung Keputusan Penerima Bantuan Rumah Layak Huni Menggunakan FMADM dan SAW," JOINTECS (Journal Inf. Technol. Comput. Sci., vol. 5, no. 3, p. 167, 2020, doi: 10.31328/jointecs.v5i3.1361.

[2] V. Listyaningsih, H. Setiawan, E. Sudrajat, and R. P. Kristianto, "DSS Pemilihan Penerima Bantuan Perbaikan Rumah dengan Metode Weight Product (WP)," Semin. Nas. Teknol. Inf. dan Multimed., no. October 2017, pp. 6-7, 2016.

[3] D. M. Efendi and N. Novita, "Weight Product Dalam Implementasi Sistem Pendukung Keputusan Bantuan Bedah Rumah,” J. Inf. dan Komput., vol. 7, no. 1, pp. 35-42, 2019, doi: 10.35959/jik.v7i1.121.

[4] L. Futiami and S. Anita, "Penentuan Supplier Bahan Baku Restaurant XO Suki Menggunakan Metode Weight Product," vol. 2, no. April, pp. 1-4, 2019. 
[5] Nurul Putri Utami, Hasanul Fahmi, and Anita Sindar, "Spk Penentuan Pemberian Pinjaman Kepada Anggota Bumdes Dengan Metode Simple Additive Weighting," SINTECH (Science Inf. Technol. J., vol. 2, no. 2, pp. 124-130, 2019, doi: 10.31598/sintechjournal.v2i2.317.

[6] M. Anwar Saputra, A. Tejawati, and Masnawati, "Sistem Pendukung Keputusan Penentuan Penerima Program Bantuan Daerah Menggunakan Weight Product," Pros. Semin. Ilmu Komput. dan Teknol. Inf., vol. 2, no. 1, pp. 76-80, 2017.

[7] I. Prayogi, P. Studi, and T. Informatika, "DAN KAWASAN PERMUKIMAN KABUPATEN DELI," vol. 1, no. 1, pp. 6-12, 2018.

[8] N. Chaniago and A. Sindar, "SPK Penilaian Hasil Belajar Siswa Menggunakan Metode TOPSIS," vol. 9, pp. 41-48, 2020.

[9] B. Baba, "Metode Weightd Product ( Wp ) Dalam Sistem Pendukung Keputusan," no. January, 2017.

[10] N. Nurjannah, Z. Arifin, and D. M. Khairina, "Sistem Pendukung Keputusan Pembelian Sepeda Motor Dengan Metode Weighted Product," Inform. Mulawarman J. Ilm. Ilmu Komput., vol. 10, no. 2, p. 20, 2015, doi: 10.30872/jim.v10i2.186.

[11] S. Firdyana, D. Cahyadi, and I. F. Astuti, "Penerapan Metode Weighted Product untuk Menentukan Penerima Bantuan Beras Masyarakat Miskin (Raskin)," Pros. Semin. Ilmu Komput. dan Teknol. Inf., vol. 2, no. 1, pp. 336-342, 2017.

[12] H. R. Hatta, M. Rizaldi, and D. M. Khairina, "Penerapan Metode Weighted Product Untuk Pemilihan Lokasi Lahan Baru Pemakaman Muslim Dengan Visualisasi Google Maps," J. Nas. Teknol. dan Sist. Inf., vol. 2, no. 3, pp. 85-94, 2016, doi: 10.25077/teknosi.v2i3.2016.85-94. 